\title{
MÁS PODEROSO QUE EL AMOR: GÉNERO, FAMILIA, PIEDAD Y POLÍTICA EN EL MOVIMIENTO CATÓLICO ESPAÑOL
}

\author{
Inmaculada Blasco Herranz
}

Más poderoso que el amor es el título de una novela publicada en 1915 por la propagandista del catolicismo social María de Echarri ${ }^{1}$. Con él, Echarri sintetizaba el comportamiento ideal con el que aleccionaba a sus jóvenes lectoras, adoptado por la protagonista de la novela. Leonor es una joven de buena familia que decide romper su compromiso con su futuro marido cuando recibe por parte de éste muestras de incredulidad e irreligiosidad. Más poderoso que el amor, por lo tanto, hace referencia a la idea de que el amor a Dios y la fidelidad a la creencia religiosa han de imponerse y prevalecer siempre, como sucede en la trama novelística, sobre el amor terrenal (para Echarri, en este caso, el amor sentido hacia un hombre-prometido-futuro esposo). Aunque este es el mensaje principal, el libro de Echarri, sin aventurarnos a enjuiciar su valor literario y teniendo en cuenta su carácter adoctrinador, constituye un material inestimable para el análisis de las concepciones que compartieron los católicos activos en las primeras décadas del siglo XX en torno a la feminidad, la masculinidad y la familia.

En este artículo proponemos analizar estos elementos, alrededor de los cuales se articularon las novelas de Echarri, entendiéndolos como aspectos constitutivos de la cultura política del movimiento católico desde sus orígenes, pues participaron también en dar forma a la manera de entender el mundo de lo que tradicionalmente se ha denominado catolicismo social y político. Si bien es cierto que los análisis y explicaciones acerca de este fenómeno han atendido principalmente a sus rasgos políticos y sociales, más recientemente

1. De ECharRi, María, Más poderoso que el amor, Barcelona, 1915. 
podemos apreciar la penetración, aunque no de forma predominante, de un enfoque de análisis cultural, siguiendo la estela de los estudios y reflexiones sobre las culturas políticas en la España de la Restauración ${ }^{2}$. En esta línea de investigación de la conformación del movimiento católico como cultura política, entendemos que resulta no sólo apropiado sino también ineludible la inclusión en el análisis de dimensiones culturales que en apariencia poco tienen que ver con la concepción de lo político, en un sentido más limitado, que formuló dicho movimiento, pero que contribuyeron a modelar la visión del mundo del mismo ${ }^{3}$.

\section{Nociones de género en el movimiento católico}

En 1901, quince años antes de la publicación de la citada obra de Echarri, había salido a la luz la que fuera primera novela de la autora católica: Los misericordiosos ${ }^{4}$. Catalogaba el prologuista dicha obra dentro de un tipo de literatura "popular e instructiva», elaborada por mujeres, a quienes consideraba «aptas para crear una literatura amena popular», que «es obra maternal». Estas obritas moralizadoras, salpicadas de breves párrafos de propaganda contrasecularizadora, y cuyo grado de difusión desconocemos, fueron concebidas, por los propios sectores católicos, como novelas cuyo fin era «recrear e instruir al pueblo». Para ello, se consideraba que las cualidades «femeninas» las impregnarían de ciertos valores especiales, muy apropiados para cumplir ese fin instructivo, inexistentes en las plumas masculinas:

2. De la Cueva Merino, Julio, «Cultura y movilización en el movimiento católico de la Restauración (1899-1913), en SUÁREZ CORTINA, Manuel (ed.), La cultura española en la Restauración, Santander, 1999, pp. 169-192; del mismo autor, «Católicos en la calle: la movilización de los católicos españoles, 1899-1923», Historia y política, no 3 (2000), pp. 55-79; y «Clericalismo y movilización católica durante la Restauración», en DE LA Cueva Merino, Julio y López Villaverde, Ángel Luis (coord.), Clericalismo y asociacionismo católico en España: de la restauración a la transición, Cuenca, 2005, pp. 27-50. La confrontación clericalismo/anticlericalismo como resultado de una dinámica de percepciones mutuas, en DE LA CUEVA MERINO, Julio y MonTero, Feliciano, «Clericalismo y anticlericalismo entre dos siglos: percepciones recíprocas», en DE LA CUEVA MERINO, Julio y Montero, Feliciano (eds.), La secularización conflictiva. España (1898-1931), Madrid, 2007, pp. 101-119.

3. La reflexión acerca de la cultura política entendida en sentido amplio, y no exclusivamente como concepciones sobre lo político, en DE DIEGO, Javier, «El concepto de «cultura política» en ciencia política y sus implicaciones para la historia», Ayer, $\mathrm{n}^{\circ} 61$ (2006), pp. 233-266. Los elementos de género de la cultura política del movimiento católico han sido analizados en BLASCO, Inmaculada, «Mujeres y culturas políticas. El movimiento católico en el cambio del siglo XIX al XX», en Femmes et Cultures politiques. Espagne XIX-XXIe siècles (en prensa).

4. DE ECHARri, María, Los misericordiosos, Novela corta, Madrid, 1901. 
«no bastarán ni la nutrida y sólida cultura, ni la firmeza de voluntad del varón más docto; no bastarán donde son necesarias las exquisitas singulares aptitudes naturales de la mujer, lo que es propio del alma femenina, en la que Dios infundió un don especial; rayo de luz, haz de mil variadas hermosuras de espíritu: la abnegación, la ingenuidad nativa, la cariñosa ternura, diligencia solícita, celo ardiente; amor, amor casi tan inmenso como el amor divino.... $\gg^{5}$.

Más poderoso que el amor narra la historia de una joven de buena familia, hija de un abogado madrileño que, aun enamorada de y comprometida con su primo, termina por rechazar abiertamente casarse con él porque éste no cree ni ama a Dios. La novela no acaba ahí, y su contenido revela mucho más que el mensaje de que ante un hombre al que se ama, pero que ha dejado de creer, una mujer sólo puede renunciar a su compromiso amoroso. Por un lado la historia continúa e introduce un segundo mensaje dirigido a las lectoras: Leonor se compromete a lograr que su primo recupere la fe, y acaba consiguiéndolo, pasando a encarnar a la mujer que reconquista el corazón del hombre para Dios. Por otra parte, en Más poderoso que el amor descubrimos unas concepciones (que se reproducen en otras novelas de Echarri, así como en otras obras de la propagandística católica) que, aunque es probable que fueran formuladas a lo largo del siglo XIX, fue a finales del mismo cuando encontraron en el movimiento católico y sus formas de expresión canales muy apropiados para su difusión masiva (en asociaciones piadosas, prensa, círculos católicos, etc.). La lectura atenta de la novela revela concepciones y significados cuya comprensión puede ayudar a establecer uno de los ingredientes más implícitos de la movilización de los clericales a comienzos de siglo.

Los dos protagonistas de Más poderoso que el amor se sostienen sobre rasgos de carácter estereotipados, que nos remiten a las imágenes dominantes, no tanto en torno a la feminidad y masculinidad ideales o esperadas, sino a lo que, en este caso, Echarri entendía que se había producido en la realidad de las identidades de género. Leonor representa el modelo ideal para las mujeres jóvenes de familias acomodadas españolas. Educada en un colegio religioso, su carácter es dulce, su alma pura y recta, su corazón misericordioso, y su fe y religiosidad de hierro. Su primo y prometido, Juan Manuel, es un hombre

5. «Prólogo escrito por José Zahonero» a Los Misericordiosos, pp. VI y VII. Zahonero citaba, como escritoras practicantes de una literatura similar, a la poetisa Carolina Valencia (esposa de Álvaro López Núñez, fundador de La Lectura Dominical y cofundador del diario católico El Universo), a Micaela Peñaranda y a la más popular Blanca de los Ríos. Desconocemos el calado que pudieron tener en la época y entre qué sectores de población. De todas las novelas de Echarri, tan sólo Redención (escrita e impresa por primera vez en 1915 junto a María Perales) fue reeditada. 
inteligente, un joven ingeniero que había cursado estudios en Alemania, donde, al entrar en contacto con el racionalismo, la ciencia y el ateísmo, comenzó a perder su fe. Juan Manuel no encarna los ideales de masculinidad católica, sino más bien su crisis, entendida como pérdida. En cierto modo, su proceso de pérdida de fe es un trasunto del proceso de secularización de la sociedad española. Pérdida de fe que para Echarri sólo podía producirse en caracteres espiritualmente débiles, que asociaba de manera naturalizada con el «sexo fuerte»:

«El respeto humano, ese auxiliar poderoso y casi invencible con que cuenta el espíritu del mal para dominar al sexo que se titula fuerte, pero que en esta materia se deja vencer con pasmosa facilidad, desde que el hombre es hombre, fue en esta ocasión también lo que dio al traste con la religiosidad de Juan Manuel, el cual empezó por dejar de ir a misa, de comulgar, y acabó por reírse de todo, por burlarse de lo que antes le era sagrado, hasta el punto de que sus mismos camaradas se extrañaban de cambio tan radical $»^{6}$.

Algo parecido, aunque inserto en una trama diferente, sucede con Carmen y Pedro, los protagonistas de Los misericordiosos. Pedro, un joven y humilde pescador, se enamora de Carmen, la hija, huérfana de madre, del propietario de la empresa donde trabajaba su padre (hasta que murió en un accidente laboral). Al no verse correspondido, y tras enterarse del compromiso de Carmen con un joven de su mismo status social acomodado, los celos llevan a Pedro a sentirse atraído por «malas compañías» e «ideologías irreligiosas». Aunque en este caso, los motivos de la pérdida de la fe son distintos que en Más poderoso que el amor, la concepción de masculinidad prevaleciente está dominada por la debilidad de espíritu, que conduce a una predisposición natural a perder la fe. Con esta pérdida, el proceso de degradación personal y moral, que incluso encuentra su reflejo en un deterioro de rasgos faciales, es muy similar en los personajes masculinos de sendas novelas: se van alejando de su familia, pierden altura moral, se vuelven hostiles a sus propias madres, toscos y malhumorados. En ambas novelas, la moralidad (que es entendida en un sentido amplio de comportamientos apropiados, de moralidad sexual y de cualidades o virtudes cívicas) y la fe aparecen íntimamente ligadas. La pérdida de la fe conduce indefectiblemente a la inmoralidad. Sólo la recuperación de la fe puede llevar a convertirse en un ser moral.

En definitiva, mientras que Leonor y Carmen son más religiosas y más fuertes espiritualmente, la tendencia dominante en ellos es la debilidad de su fe, que procede bien del predominio de la razón que ha sido tentada por

6. De EChARri, María, Más poderoso que el amor..., p. 45. 
el materialismo, bien del dominio de pasiones y emociones negativas como la envidia o los celos. Tanto en Los misericordiosos como en Más poderoso que el amor, el personaje masculino sucumbe con facilidad a «doctrinas falsas» y muestra una debilidad espiritual que se traduce en debilidad moral. Aunque una parte del estereotipo de la mujer doméstica virtuosa se reproduce en las cualidades de dulzura, entrega, bondad e inocencia, se trata de mujeres que toman decisiones importantes para su vida sin consultar a nadie y sin que la duda las ensombrezca. A ellas se les atribuye fortaleza y resolución. Y esa fortaleza las convierte en sujetos salvadores, que pueden encauzar con éxito por la buena senda de la fe a unos hombres fácilmente atraídos por el materialismo, la ciencia, la inmoralidad o el socialismo.

Estas concepciones sobre género y religión pueden rastrearse no sólo en las novelas de Echarri sino también en la variedad de escritos dirigidos a las mujeres por los propagandistas católicos, tanto clero como seglares ${ }^{7}$. Decenas de artículos publicados en la prensa católica, folletos y libros vieron la luz entre la última década del siglo XIX y las dos primeras del XX, destinados a definir qué era una mujer, establecer sus roles apropiados en la sociedad y determinar en qué maneras podían participar en la lucha contrasecularizadora inicialmente, y, más adelante, en las iniciativas del catolicismo social.

En una constante que abruma por su repetición, las mujeres fueron presentadas como más religiosas. El modelo de mujer sobre el que se sustentaba esta visión remite a una concepción moderna de la naturaleza humana,

7. Por referir sólo algunos, que pueden añadirse a los citados en este artículo: GómEZ, Valentín, Acción social de la Mujer en Madrid, Madrid, 1904; AvILÉS PÉREZ, J., Pbro., La Mujer Sevillana. Artículo Premiado en los Juegos Florales del Ateneo Sevillano, enriquecido con varias adiciones y la crítica del feminismo, Sevilla, 1906; MONSERdÁ De MACiÁ, Dolors, El feminismo á Catalunya, Barcelona, 1907; de esta misma autora, Estudi feminista. Orientacions per a la dòna catalana, Barcelona, 1909; AlARCÓN y MELÉndEZ, Julio, Un feminismo aceptable, Madrid, 1908; DE ECHARRI, María, El trabajo a domicilio de la mujer en Madrid (prólogo de José Monge y Bernal), Sevilla, 1909; DE ECHARRI, María, «Acción Social de la Mujer» en Semana Social de España. Segundo Curso, Valencia, 12-19 de diciembre de 1907, Zaragoza, 1908, pp. 417-448; CASANOvAS, P. Ignacio, «Acción de la mujer en la vida social» en Estudios Sociales, 1952 (conferencias de 1911); del mismo autor, Apostolado de la mujer, Barcelona, 1912. A esto habría que añadir los artículos en la prensa católica y las traducciones de los ensayos de católicos-sociales europeos como Max Turmann, Esteban Lamy, Antonin D. Sertillanges, y los jesuitas Victor Van Tricht y Antonio Pavissich. Estas fuentes han sido analizadas con mayor detalle en otros trabajos: BLASCO, Inmaculada, «'Sí, los hombres se van ': discursos de género y construcción de identidades políticas en el movimiento católico», en Nicolás, Encarna y GONZÁLEZ, Carmen (eds.), Ayeres en discusión. Temas clave de Historia Contemporánea hoy, Murcia, 2008; y «Género en la cultura política del movimiento católico: la construcción de una identidad política para las mujeres españolas», en 39th Annual Conference of the Spanish and Portuguese Historical Society, Texas, 2008. 
que era divida en dos esencias complementarias: hombres y mujeres, con la misma alma pero con diferente reparto de cualidades relacionadas con dos dominios que se entendían en relación: el del corazón y el de la razón. En las mujeres tenía mayor peso el corazón, lo que las hacía más proclives a los sentimientos, las emociones y también a una religiosidad más intensa. En los hombres, la razón predominaba sobre el corazón, y con ello, todas las virtudes relacionadas con la primera. El problema de pérdida de fe en los hombres, que venían diagnosticando la Iglesia y los católicos desde mediados del siglo XIX residía no tanto en un exceso de razón, sino en que ésta había dejado de estar informada por la fe (en que se habían separado dos ámbitos que en los seres humanos permanecían naturalmente unidos), lo cual permitía la entrada en juego de las pasiones. El senador católico Polo y Peyrolón ofrecía una imagen muy popularizada entre sus correligionarios, que representaba al hombre del XIX deteriorado por el materialismo, las pasiones carnales, y una fe demasiado superficial:

«(...) cuando del sexo fuerte se trata, el ánimo se contrista y el porvenir se presenta negro y pavoroso, como nube preñada de tempestades. El hombre del presente siglo, hijo predilecto de la mal llamada civilización moderna, vive sumergido en tan subida atmósfera de naturalismo irracional (...) Su Dios es su vientre, y en él ha levantado su trono á todas las concupiscencias y sensualidades. Su fe, no pasa de la corteza de las cosas y aunque aparente lo contrario, en la vida práctica se atiene sólo á lo que ve y toca» ${ }^{8}$.

Los hombres habían sido perdidos para la fe debido a que la razón había dejado de estar guiada por aquélla, tal y como les sucedía a los dos protagonistas masculinos de las novelas de Echarri aquí citadas. Que constituyera algo lógico que los hombres se dejaran llevar por sus pasiones y se alejaran de la religión mientras que un fenómeno similar entre las mujeres produjera gran extrañeza y escándalo evidencia en qué medida la visión católica había naturalizado las expectativas atribuidas a los sexos en materia religiosa y moral:

«Que el varón, acostumbrado a los goces de la vida, a llevar adelante sus antojos y a engendrar errores, se desvíe de nuestra Religión augusta y llegue a apostatar de ella, triste es, pero no extraña. Pero que la mujer, acostumbrada a apurar los cálices amargos, a ser víctima de los caprichos varoniles y a ser más moral y piadosa que el hombre, de forma a los errores de éste, y (...) marche con ellos por el extraviado derrotero que aquél anda, esto no sólo extraña, sino pasma en sumo grado»?

8. Polo Y PeYrolón, Manuel, «Apostolado de la mujer en las sociedades modernas», en Discursos académicos, Valencia, $2^{\mathrm{a}}$ ed., 1891, pp. 93-127 (aquí, p. 107).

9. De Burguera Y Serrano, Amado, Acción católico-social de la mujer. Lo que fue en lo pasado, lo que es en los actuales tiempos y debe ser en lo porvenir, Valencia, 1909, p. 246. 
Esta percepción cada vez más extendida de que los hombres habían abandonado la religión, y se habían dejado arrastrar por las pasiones y las falsas ideologías tenía fuertes implicaciones para el modelo de masculinidad ideal defendido por los católicos. Un modelo que, lejos de fijar su cometido tan sólo en la esfera pública, cifraba unas atribuciones bien definidas en el seno de la familia. En consecuencia, el impacto de la secularización también se dejó sentir sobre la capacidad de los hombres para cumplir con los cometidos que se les exigía en un hogar verdaderamente cristiano.

\section{Dentro de la familia católica}

Los fundamentos de la visión católica en torno a la familia hundían sus raíces en viejas formulaciones cuyos términos se habían ido adaptando a nuevos lenguajes. A la altura de finales del siglo XIX, la familia era entendida, en el seno de los sectores católicos, como núcleo primigenio de la organización social («base fundamental de la sociedad civil»), un «organismo intermedio é indispensable» entre el estado y el individuo, cuyo principio era el matrimonio canónico e indisoluble ${ }^{10}$. En esta sociedad doméstica, como llamaba León XIII al matrimonio en su encíclica Arcanum, el marido era el príncipe y cabeza de la mujer, con la cual establecía una relación jerárquica, basada en la sumisión y la obediencia. Como resultado de la influencia del discurso de la domesticidad, que el propio catolicismo contribuyó sin duda a configurar en España, a la altura de finales del siglo XIX dicha visión aparecía habitualmente completada con la idea de que «la sumisión y la obediencia no rebajan en nada la condición de la mujer en el matrimonio», pues tanto dicho sacramento como la institución familiar habían contribuido y contribuían a ennoblecerla ${ }^{11}$.

El modelo de familia católica exigía, por lo tanto, de un padre y una madre, hombre y mujer, que encarnaran una serie de virtudes adecuadas a su sexo. Quizás es más conocida la imagen ideal de mujer que cultivó el catolicismo, y que entroncaba con el ideal de domesticidad imperante en España durante la segunda mitad del siglo XIX. El modelo católico de mujer contenía una serie de virtudes (que se asociaban con el predominio del corazón y el espíritu maternal) que la hacían diferente al hombre, virtudes que debía cultivar

10. La última cita, en OMS, Antonio, «Discurso del M.I. Sr. D. Antonio Oms, penitenciario de la Catedral de Gerona», en Crónica del cuarto congreso católico español. Discursos pronunciados en las sesiones públicas, reseña de las memorias y trabajos presentados en las secciones y demás documentos referentes a dicha asamblea, celebrada en Tarragona en Octubre de 1894, Tarragona, 1894, pp. 365-375 (aquí, p. 367). La anterior, en MiR Y NOGUERA, Juan, El triunfo social de la Iglesia católica. Tomo primero, Madrid, 1910, p. 393.

11. OmS, Antonio, «Discurso del M.I. Sr. D. Antonio Oms...», p. 369. 
y educar. Estas virtudes eran idóneas para unas tareas precisas -una misión-, relacionadas con el mantenimiento del hogar, la educación de los hijos (entendida como «ordenar según la ley y las buenas costumbres la voluntad y los movimientos pasionales; así como la instrucción tiene por objeto el cultivo de la inteligencia»), y como ya vimos antes, la preservación de la moralidad y la fe dentro del núcleo familiar ${ }^{12}$. En definitiva, las mujeres eran concebidas como destinadas «por regla general, á constituir por el matrimonio una nueva familia y á ser en ella la nota dominante y característica (...). Para eso la creó Dios y para el cumplimiento de tan hermosa misión dotóla con las virtudes de su corazón admirable». Era ese corazón lo que movía «la inteligencia del hombre hacia lo que es bueno, noble y honrado» ${ }^{13}$.

Menos estudiado ha sido el ideal masculino y paterno esperado dentro de la familia católica. Los hombres debían ser, ante todo, amantes de su religión y de su patria, un apoyo en la educación de sus hijos, trabajadores y honrados, la encarnación del principio de autoridad, poseedores de autocontrol sobre las pasiones, y cultivadores de la vida en familia:

«Hay muy pocas familias, relativamente, que merezcan con justicia el nombre de cristianas, de rectamente ordenadas. Un padre irreprensible, trabajador y diligente, que guarda a su esposa fidelidad inquebrantable, que ayuda a la educación de los hijos con rectitud templada por la prudencia y el amor, que cuida de la hacienda con esmero, sin jamás rozar el campo de lo injusto; una esposa amante, recogida y modesta, que educa a sus hijos con ilustrado celo, hace del hogar un nido de tranquilidad y alegría, cuida de los criados y dependientes con dignidad y con cariño y administra sabiamente la casa; unos hijos obedientes, aplicados, de limpias costumbres; todo esto es muy hermoso, pero es difícil; todo esto tiene hoy muchos y poderosos enemigos» ${ }^{14}$.

Pero lo realmente novedoso en el discurso del movimiento católico difundido en torno a la familia a finales del siglo XIX, aunque no fuera exclusivo de él, fue la visión de este ideal familiar atacado en su moralidad e integridad por las «modernas costumbres», que provocaban la desunión de sus miembros. Todas las reflexiones católicas consultadas sobre la familia contienen un capítulo dedicado a desgranar los «males que aquejan a la familia actual». Y uno

12. Jordi Canal destacó la importancia de las tareas atribuidas a las mujeres en la perpetuación de los valores y principios del carlismo. En CANAL, Jordi, «La gran familia. Estructuras e imágenes familiares en la cultura política carlista», en CRUZ, Rafael y PÉREZ Ledesma, Manuel (eds.), Cultura y movilización en la España contemporánea, Madrid, 1997, pp. 99-136.

13. Esta cita y la anterior, en OMS, Antonio, «Discurso del M.I. Sr. D. Antonio Oms...», p. 372.

14. BilbaO, Félix, Orientaciones femeninas, Valencia, 1916, p. 18; véase también El Pilar, no 1272, 11-I-1908, p. 11. 
de los elementos que más sorprende de este discurso, quizás porque no ha sido destacado como relevante y específico de la visión católica finisecular en torno al tema, es que los reproches por haber contribuido al deterioro familiar iban dirigidos, aunque no en exclusiva, a los hombres y a las nuevas formas de sociabilidad masculina que parecían ir calando en la nueva sociedad de masas:

«Contraria a esta unidad y vida indivisa es toda discrepancia de caracteres, intereses ó afectos; en sociedad tan reducida el dualismo es la muerte. Como fomentadoras de este dualismo, y por tanto enemigas naturales de la familia, deben ser consideradas en general las sociedades llamadas de recreo, en las cuales buscan los hombres un solaz que no encuentra, ó no saben encontrar, en casa. Difícilmente puede admitirse la necesidad cotidiana de buscarlo fuera de ella y entre extraños, sin que resulte un hecho, que es por sí sólo síntoma de pronóstico grave para la vida de familia, á saber: que el hombre de negocio, el hombre de trabajo no encuentra al lado de su mujer y de sus hijos el apacible descanso, la expansión y los placeres de la amistad que necesita buscar entre extraños (...) he de denunciar el casino como enemigo natural de la casa». ${ }^{15}$

El otro elemento contrario al ideal de familia atañía a las mujeres. Mientras que a los hombres se les culpaba de abandonar la familia en busca de placeres fuera de ella, a las mujeres se les increpaba su abandono debido al trabajo en la industria. El «trabajo en las fábricas de la mujer casada» afectaba de muchas maneras al bienestar familiar: atacaba a la esencia de la feminidad, degradaba a la mujer, la apartaba de aquellas cualidades relacionadas con el corazón de la mujer-madre, afectaba a su constitución física de ésta y a la salud de la descendencia, y repercutía en la higiene familiar y social. Para un ideal de mujer regido por una feminidad del sentimiento, la dedicación excluyente a la crianza y educación de los hijos y a la conservación del bienestar familiar en el plano material y moral, el trabajo en la fábrica constituía una auténtica aberración, una desnaturalización del sujeto femenino y de sus funciones sociales:

«La mujer para no degenerar de su tipo ideal y ser, como debe, la dulce compañera del hombre, necesita de la casa y de su ambiente (...) ¿Cómo podrá la esposa obrera ofrecer á su marido la suya, aseada y apetecible, ó mejor, cómo no tenerla desaseada y mugrienta, si pasa todas las horas útiles del día en las cuadras, de las que sale con los brazos cansados, la cabeza atontada por la monotonía del trabajo, y el corazón oprimido, sin acción y sin libertad, por ritmo invariable de los grandes talleres? ¿Cómo podrá la madre obrera criar y educar á sus hijos, que es la primera y dulcísimo misión de la mujer en el mundo y donde brillan las dotes de su corazón privilegiado? ¡Ah! si alguna

15. Oms, Antonio, «Discurso del M.I. Sr. D. Antonio Oms..., p. 370. 
madre obrera, al tomar á su hijo en los brazos en las horas de descanso, calcula fríamente los jornales que ha perdido para poner aquel su hijito en el mundo, ¡qué rebajamiento tan profundo revelaría este desvío de las facultades afectivas en el corazón de aquella infeliz madre!» ${ }^{16}$.

Por este motivo, gran parte de los católicos sociales, dentro y fuera de España, se opusieron en sus escritos al trabajo de la mujer, sobre todo en la industria, o propusieron, como solución posibilista, limitarlo y regularlo ${ }^{17}$. El objetivo último era «afianzar la moralidad y bienestar de la familia», proteger el hogar de los obreros apelando a la idea de la familia como célula social imprescindible en tanto que primigenia, pues «si no hay vida doméstica no hay vida nacional, social o política ${ }^{18}$.

Este fue uno de los aspectos de la secularización que más llegó a preocupar a los católicos (y sin embargo, escasamente incorporado a los estudios sobre el proceso de secularización y su percepción): cómo las nuevas costumbres, prácticas e ideologías habían llegado a deteriorar (y seguían haciéndolo) las virtudes domésticas ideales esperadas en padres, madres e hijos para mantener una unidad familiar modelo:

«El casino o la taberna, los espectáculos para hombres, los negocios más o menos arriesgados, el juego con su mirada fascinadora como de serpiente, para el padre; el lujo, la frivolidad, los teatros, la ignorancia y falta de preparación para la vida del hogar, los paseos, las tiendas, la escasez misma, hermana del desaliño y de la pereza, en la mujer; las amistades, las lecturas, el ambiente, los cines, los círculos, para los hijos y las hijas; todo ese conjunto de cosas forman un ejército contra el hogar, y muchas veces, por desgracia, sus tiros hacen fatales blancos» ${ }^{19}$.

Ante la degradación de la familia y las amenazas que se cernían sobre ella, el catolicismo formuló y difundió un ideal familiar que atesoraba todas estas virtudes y que restauraba a la familia por excelencia del relato bíblico, la sagrada familia de Nazareth. En ella reinaba la felicidad, la armonía y la paz porque todos sus miembros cumplían las virtudes exigidas según su condición: «un

16. Ibidem, pp. 370-371.

17. Mientras que uno de los referentes extranjeros en la materia, José BIEDERLACK, profesor de la Universidad Gregoriana de Roma, se mostraba en contra del trabajo de la mujer y proponía que «lo mejor sería prohibirlo absolutamente en las grandes industrias» ( $\mathrm{La}$ cuestión social. Principios fundamentales para su estudio y solución, Burgos, 1908), en España, MiR Y NOGUERA sugería reglamentarlo, junto con el de los niños, «para devolver las esposas á los hogares, las madres á las cunas de sus niños, y facilitarles á éstos formación física y moral», en El triunfo social de la Iglesia católica..., p. 416.

18. Las citas en Mir Y Noguera, Juan, El triunfo social de la Iglesia católica..., pp. 416-417.

19. Bilbao, Félix, Orientaciones femeninas..., p. 18. 
esposo santo, una virgen pura y el más sumiso y amante de los hijos» ${ }^{20}$. Sin embargo, era la mujer la que estaba llamada a cumplir el papel principal no sólo en la conservación de la familia sino en la redención del hombre dentro y fuera de ella. Como resultado de constatar la tendencia masculina a ser dominado por las pasiones y arrastrado hacia la indiferencia religiosa (en el mejor de los casos), y esperar la excelencia moral y religiosa en las mujeres, éstas fueron convertidas en sujeto ejecutor del necesario rescate o salvación del hombre de la caída-redención.

Si regresamos por un momento a las novelas de Echarri, el colofón de las mismas contiene precisamente el relato de cómo Carmen y Leonor actúan como sujetos redentores que logran, a través de una mediación más o menos directa, que los hombres perdidos para la fe vuelvan al redil de la confesión católica. Como decía Polo y Peyrolón en 1891: «Tarea espinosa, pero no imposible, ha de ser por lo tanto la conversión de hombres tales, sin creencias, sin virtudes y dados en cuerpo y alma á la vida muelle y regalona (...) ¿Quién convierte á estos desventurados?». Al igual que senador carlista, el periodista J. Le Brun estaba convencido de que sólo podían ser las mujeres: «iY quién defenderá las puertas de ese pequeño paraíso de la tierra, que llamamos hogar cristiano? ¿Quién sino la mujer con la espada de fuego de su fe, de su piedad y su celo $(\ldots) ? »^{21}$.

\section{Las mujeres redentoras: entre la piedad y política}

La conferencia de Pidal y Mon «El feminismo y la cultura de la mujer», pronunciada en 1906, pareció tener gran impacto entre los publicistas católicos que se fueron especializando en escribir sobre y para las mujeres ${ }^{22}$. En ella, entre otros elementos como la crítica feroz a lo que él denominaba «feminismo igualitario», destacaba el leit motiv de la mujer como regeneradora o redentora de la civilización, de las costumbres y de la sociedad, debido a su papel central en lo que, al fin y al cabo, era considerada la piedra angular de la sociedad, la familia:

20. El Pilar, $\mathrm{n}^{\circ} 1274,25-\mathrm{I}-1908$, p. 25.

21. Le Brun, J., La mujer y la prensa, Zaragoza, 1908, p. 21; y POlo Y PeYrolón, Manuel, «Apostolado de la mujer..., pp. 107-108. Peyrolón detallaba distintas situaciones de conversión de los hombres por las mujeres: «La mujer-hija ha ejercitado el apostolado convirtiendo al hombre-padre» (p. 111); «la mujer-hermana para evangelizar al hombre-hermano» (p. 112); «la novia verdaderamente cristiana ha evangelizado y evangeliza (...) á no pocos jóvenes disipados!» (p. 117); «la esposa cristiana evangelizando al hombre-marido» (p. 120); «la mujer-madre puede y debe evangelizar al hombre-hijo» (p. 122).

22. Pidal y Mon, Alejandro, El feminismo y la cultura de la mujer, Madrid, 1906, 
«Lejos de oponerse a la instrucción y cultura de la mujer, urge que ésta recobre por el estudio y la cultura el ascendiente que debe ejercer sobre las costumbres, y por las costumbres en la sociedad, en la civilización y el progreso. Urge que, dándose cuenta del calor de los sagrados principios y de los santos intereses que representa en la sociedad, por el intermedio de la familia, no se los deje oprimir, arrebatar ni escarnecer por indefensa ni por cómplice, y salga a su defensa con valor, ya con su influencia social, ya con sus derechos legales, conforme los merezca y adquiera ${ }^{23}$.

En este misma línea, J. Le Brun defendía la participación de las mujeres en la buena prensa esgrimiendo esta concepción de la mujer como reserva espiritual y último reducto de la fe que debía activarse ante el panorama de unos hombres desorientados, arrastrados por ideas erróneas:

«La mujer, conduciendo de la mano al hombre entre el dédalo angustioso de mil opiniones y de mil criterios, y conduciéndolo hasta la plena posesión de la verdad... ipuede darse mayor empresa al celo de una cristiana? Los hombres han corrompido la prensa y se pierden bebiendo en sus aguas ponzoñosas. La mujer purificará los manantiales y saciará la sed de los sedientos con abundancia de aguas refrigerantes y claras $»^{24}$.

En efecto, la aparición de la mujer como sujeto de salvación, que podía desplegar su evangelización instintiva en la familia y fuera de ella, se apoyaba sobre este complicado entramado de significados de género que hemos intentado desentrañar en los epígrafes anteriores. Y en torno al mismo se articuló también la que pareció ser la vía de salvación por excelencia en el último tercio del siglo XIX, el cultivo de la piedad. La piedad se contaba entre las virtudes de corazón, y rasgo, por lo tanto, de feminidad. Si las mujeres eran más religiosas, era lógico que también fueran más piadosas. Y lo eran, igual que su religiosidad, por naturaleza, porque sus cualidades innatas las acercaban más a la práctica piadosa, a la comunicación con Dios. De hecho, el cultivo de la piedad y la práctica de la caridad habían sido las dos principales actividades movilizadoras fuera del hogar de las jóvenes mujeres de la burguesía en el último tercio del siglo XIX. Esto formaba parte de un fenómeno escasamente estudiado, el que Frances Lannon denominara «renacimiento católico», y que sentó las bases para el despegue del movimiento católico (y especialmente el protagonizado por mujeres) durante el cambio de siglo ${ }^{25}$. Junto al incremento

23. PidAl y Mon, Alejandro, El feminismo..., p. 9.

24. LE BRUn, J., La mujer y la prensa..., p. 7.

25. LANNON, Frances, Privilegio, persecución y profecía. La Iglesia Católica en España, 18751975, Madrid, 1990 ( $1^{a}$ ed. inglesa, 1987), pp. 81-112. Acerca de una de las dimensiones del renacimiento católico, el del aumento de vocaciones religiosas, véase MORENO, Mónica, «Religiosas, jerarquía y sociedad en España, 1875-1900», Historia Social, nº 38 (2000), pp. 57-71. 
de las vocaciones religiosas, llegó a convertirse en un hábito social que las hijas de las buenas familias urbanas se inscribieran en una sociedad pía o de caridad (o en ambas) como una manera de cumplir con sus obligaciones sociales y religiosas. Crecieron, en paralelo a las órdenes religiosas dedicadas a la vida activa, las terceras órdenes, las Conferencias de San Vicente de Paúl, y las confraternidades piadosas como las Hijas de María, y en general, cualquier tipo de asociaciones de cultivo de la piedad. Y esto sucedió no sólo en España, sino que se ha constatado un movimiento similar, con distintos ritmos, en otros países europeos ${ }^{26}$.

El cultivo de la piedad interior, la práctica de la oración individual y colectiva, el mantenimiento y difusión de los rituales católicos, de devociones viejas y nuevas eran los cometidos de este asociacionismo, que no hicieron sino reforzar, al confirmarlo en la práctica, el vínculo entre religiosidad y feminidad. Pero además, constituían mecanismos que generaban una identidad católica precisa, más sentida y politizada, así como lugares donde se educaba el sentimiento, y se forjaban comportamientos sociales y morales apropiados para las jóvenes católicas ${ }^{27}$. Las terceras órdenes, como la Franciscana (en la que se había iniciado en su juventud María de Echarri, y a la cual permaneció vinculada toda su vida), llegaban a plantear una forma de vida diferenciada basada en un compromiso espiritual más cercano al de los religiosos, aunque siguieran siendo seglares ${ }^{28}$.

26. Dau Novelli, Cecilia, Società, chiesa e associazionismo femminile: l'Unione fra le donne cattoliche d'Italia (1902-1919), Roma, 1988; DE GIORGIO, Michela, «La creyente», en FrEVERT, Ute y HAUPT, Heinz-Gerhard (eds.), El hombre del siglo XIX, Madrid, 2001, pp. 147-185.

27. Los actos de piedad, devoción y desagravio públicos como mecanismos de fortalecimiento de la identidad católica, en SALOMÓN CHÉLIZ, Pilar, «Anticlericalismo y sociabilidad católica en el tránsito del XIX al XX en Aragón», en SÁNCHEZ MANTERO, Rafael (ed.), En torno al «98». España en el tránsito del siglo XIX al XX. Actas del IV Congreso de la Asociación de Historia Contemporánea, tomo I, Universidad de Huelva, 2000, pp. 503-511; y, de la misma autora, «¿Espejos invertidos? Mujeres clericales, mujeres anticlericales», Arenal, vol. 11, nº 2 (2004), pp. 87-111; también DE LA CUEVA MERINO, Julio, «Católicos en la calle»...

28. Los terciarios seculares «viviendo en el siglo, bajo la dirección de alguna Orden y conforme al espíritu de la misma, se esfuerzan por adquirir la perfección cristiana de una manera acomodada a la vida en el siglo, según las reglas para ellos aprobadas por la Sede Apostólica» (en Gran Enciclopedia Rialp: (http://www.canalsocial.net/GER/ficha GER.asp?id=11444\&cat=religioncristiana). Es decir, dependen de una orden religiosa, reciben de ella orientación espiritual, pero son laicos (viven en el mundo). En el caso de las terciarias franciscanas, se trataba de mujeres no casadas (salvo consentimiento del marido), que llevaban escapulario pequeño y cordón, y que hacían un año de noviciado. En cuanto a las normas de vida, debían abstenerse de bailes, teatros licenciosos, y de comilonas; ser moderadas en el vestido; frugales en comida-bebida; confesarse 
Este asociacionismo piadoso, que vivió su época de esplendor durante la Restauración, se fue impregnando de una visión combativa del catolicismo, que acabó siendo uno de los rasgos de la cultura política católica en todas sus manifestaciones, como fortaleza asediada que había que defender ${ }^{29}$. Aunque este proceso, así como los rasgos generales de las entidades piadosas y de caridad seglares, no ha sido estudiado en profundidad, lo que sí que podemos constatar es que, a la altura de principios de siglo, se hace visible una movilización masiva protagonizada mayoritariamente por estas entidades, que requería de una identidad política católica de rasgos fuertemente contrasecularizadores y clericales.

Cuando, a comienzos de siglo, el anticlericalismo y los gobiernos laicistas amenazaron con recortar los privilegios de la Iglesia católica, multitud de asociaciones femeninas piadosas y de caridad se movilizaron en defensa de los intereses católicos en el ámbito público. Y lo hicieron de dos maneras. La primera suponía una continuidad de prácticas pasadas, como era el impulso y participación en demostraciones de devoción pública y masiva (procesiones, ceremonias de desagravio y perdón por los pecados). Ahora bien, éstas iban adquiriendo unos significados cada vez más politizados y agresivos, tanto para los practicantes como para sus adversarios, que expresaban la capacidad de atracción y convocatoria de los clericales frente a anticlericales y laicistas, y contribuían a afirmar una identidad católica combativa. En realidad, el cultivo de la piedad interior, la práctica de cultos y costumbres católicas pasaron a ser entendidos como el primer paso imprescindible para fortalecer la fe frente a los ataques externos de la secularización, el anticlericalismo y la inmoralidad que ambos acarreaban ${ }^{30}$.

Ejemplo de ello fue la peregrinación al santuario y coronación de la Virgen del Pilar, impulsada por el entonces obispo de Madrid-Alcalá, Guisasola, en 1904, a instancias de las mujeres católicas de Zaragoza, y con el respaldo masivo de las mismas ${ }^{31}$. También colaboraron, aunque su participación quedó

todos los meses; rezar determinadas oraciones; practicar una caridad y benevolencia cuidadosa; hacer examen de conciencia, no jurar, etc. En ECHARRI, María, La terciaria según el espiritu de San Francisco, Madrid, 1914.

29. De La Cueva Merino, Julio, «Cultura y movilización...», pp. 178-183.

30. Procesiones, devociones y peregrinas analizados como recursos movilizadores tradicionales de la Iglesia, en DE LA Cueva Merino, Julio, «Católicos en la calle...», pp. 60-65.

31. SAlOMÓN CHÉliz, Pilar, «¿Espejos invertidos?...», pp. 87-111. En una noticia que informa sobre la primera reunión preparatoria, mantenida por el obispo de Madrid-Alcalá y el arzobispo de Zaragoza con las «más distinguidas damas de nuestra sociedad», que transcribe parte del discurso de Guisasola, prelado de Madrid por aquel entonces, no queda claro de quién fue la iniciativa originariamente. Así, el diario relata: «Empezó el Sr. Guisasola por dar las gracias a las señoras reunidas, quienes con su presencia 
algo más diluida dentro de una movilización de grandes magnitudes, en la celebración del Jubileo sacerdotal, la peregrinación al Pilar, y la celebración del Congreso Eucarístico, en 1908, que coincidió con el centenario de la Guerra de Independencia.

Una segunda vía, protagonizada por las mismas mujeres que se volcaron en las prácticas piadosas y devocionales, fue más novedosa. Se trataba de adoptar una forma de actuación pública que implicaba ir más allá de las habituales prácticas piadosas, acudir a la prensa, protestar masivamente frente a las autoridades, en definitiva, hacer abiertamente política clerical o contrasecularizadora $^{32}$. Es cierto que durante el Sexenio encontramos demostraciones similares en defensa de la religión que se percibió atacada, pero es a comienzos del siglo XX cuando tuvo lugar una movilización masiva de la opinión pública católica femenina con motivo del proyecto de ley de asociaciones de $1906^{33}$. Entre noviembre de 1906 y enero de 1907, la prensa católica lanzó una ofensiva en la que se recogían firmas y adhesiones contra lo que se consideró como «el primer acto de la persecución decretada con la Iglesia», el proyecto de ley de Asociaciones ${ }^{34}$.

respondieron a la invitación del prelado para organizar la peregrinación al Pilar»; seguidamente, reproducía las siguientes palabras del obispo: «con alma y vida hube de adherirme al proyecto, ofrecí mi cooperación, y di mi nombre y mi firma para convocar a las damas católicas a esta reunión». El Noticiero, 23-VI-1904, p. 1.

32. Aunque se negara que la actuación fuera política, en la medida en que se concebía como religiosa: «(...) porque este es un acto que tiene una importancia grandísima, tanto mayor cuanto que no es político, sino religioso, y, naturalmente, siendo lo segundo y no teniendo nada que ver con lo primero, ha de llevar en sí una fuerza, una verdad, una magnitud que no entraña ninguno de los que se relacionan con la política; en éstos son hombres inspirados por hombres y por pensamientos humanos, los que hablan, y los que traducen en palabras más o menos fogosas y elocuentes sus ideas; aquí seremos mujeres las que nos hayamos reunido, pero no inspiradas por nada que a la parte social y material se refiera, sino alentadas por la idea de defender a nuestra santa religión, la tratada y perseguida, de defender a los que forman la vanguardia de la milicia de Cristo», El Universo, alocución de María de Echarri en el palacio de la duquesa de Bailén, donde se reunieron dos mil señoras, 3-XII-1906, p. 1. Se pueden seguir las adhesiones y protestas de diferentes entidades y lugares, en El Universo, 20, 21, 22 y 26-XII-1906 y 5,8 y 9-I-1907.

33. La referencia al Sexenio, en ESPIGADO, Gloria, «Conciencia y acción política de las mujeres durante el Sexenio Democrático (1868-1874)», en XIII Coloquio Internacional de la AEIHM. La Historia de las Mujeres. Perspectivas actuales, Barcelona, 19-21 de Octubre de 2006.

34. Julio de la Cueva subraya el punto de inflexión que supusieron las movilizaciones de 1906 contra el proyecto de ley de Dávila en cuanto a repertorio de protesta de los católicos, quienes comenzaron a reclamar para sí el mitin y la manifestación (a imitación de sus rivales republicanos y laicistas), por su condición de ciudadanos. DE LA CUEVA MERINo, Julio, «Católicos en la calle...», pp. 65-68. 
De entre los muy variados apoyos contra el proyecto, destacó (y así lo puso de relieve una prensa interesada en mostrar que los católicos aventajaban a sus rivales en lo que a respaldo femenino se refería) un muy vital asociacionismo católico femenino de carácter mayoritariamente piadoso-caritativo. Por citar tan solo un ejemplo de los muchos que pueden extraerse de los diarios católicos, las entidades navarras que enviaron sus firmas de protesta eran las siguientes: la VOT de San Francisco, la VOT de Nuestra Señora del Carmen, el Apostolado de la Oración, la Archicofradía de la Guardia de Honor del Sagrado Corazón de Jesús, las Hijas de María, la Propagación de la Fe, la Archicofradía de Nuestra Señora del Perpetuo Socorro, la Semana Devota de Nuestra Señora del Carmen, las Conferencias de SVP, la Escuela Dominical, el Apostolado de Damas Catequistas, la Escuela doctrinal de San Juan Bautista.

Las damas católicas eran conscientes de que esta acción suponía una transformación de lo que, hasta el momento, se habían considerado formas apropiadas de participación femenina. Su mayor novedad era cifrada en su carácter de actos «públicos y colectivos». Así, las señoras navarras afirmaban lo siguiente en su súplica dirigida a la reina Victoria:

«Nosotras, señoras, que en la profesión de la sacrosanta Fe ciframos los alientos y la significación de nuestra vida (...) no queríamos ni debíamos permanecer apartadas de ese movimiento de protesta, ni desatender los ejemplos y las exhortaciones del Episcopado, aunque para solidarizarnos hubiésemos de sacrificar la natural modestia de nuestro sexo, no habituada a esos actos públicos y colectivos» ${ }^{35}$.

Esta movilización suscitada por un acontecimiento preciso como fue el proyecto de ley de Asociaciones volvería a repetirse en otros momentos de dicha década y de la siguiente, al ritmo de las acciones anticlericales o de las iniciativas laicistas en el gobierno ${ }^{36}$. Sin embargo, la potencialidad política tanto individual como colectiva de las entidades femeninas piadosas y de caridad que habían prosperado durante las primeras décadas de la Restauración se había materializado unos años antes, a raíz de los primeros conflictos anticlericales que se produjeron nada más estrenarse el siglo. Entre la variada respuesta contrasecularizadora de los católicos, habría que destacar el surgimiento de organizaciones católicas femeninas estrechamente vinculadas a los centros de defensa social y a las ligas católicas, como fue el caso, que conozcamos, de Zaragoza y Valencia. Tanto la Corte de Honor como Protección de Intereses Ca-

35. El Siglo Futuro. Diario Católico, 6-XII-1906.

36. De La Cueva Merino, Julio, «Católicos en la calle...», pp. 57-59; y SAlomón ChÉliz, Pilar, «¿Espejos invertidos?...», pp. 91-92. 
tólicos surgieron como respuesta a las agresiones anticlericales que tuvieron lugar en 1901 en ambas ciudades.

Lo más interesante de estas dos entidades es que representan el paso de una modalidad de acción a la otra (de una más piadoso-devocional a otra de cariz político, aunque esta última fuera entendida y presentada como de raíz religiosa). La Corte de Honor de Nuestra Señora del Pilar (1902) afirmaba haberse constituido con un fin devocional (la extensión del culto, así como el cultivo de la piedad interior de las socias), pero su surgimiento estaba íntimamente ligado a la protesta frente a sucesos anticlericales:

«Tristes recuerdos me trae el 18 de julio de 1901. Más vale que los calle, pero de los sucesos ocurridos aquel día en Zaragoza surgió con más entusiasmo el proyecto de nuestra fundación. Se quiso desagraviar á la Santísima Virgen del Pilar y se hicieron funciones religiosas, se levantó por suscripción patriótica una torre en su templo y quedó acordado fundar la Corte de Honor (...) La Corte de Honor se fundó para dar culto á la Virgen del Pilar (...) Se fundó para extender la devoción á la Corte del Pilar» ${ }^{37}$.

No fue sin embargo la extensión del culto la única ni siquiera la más estimada ocupación de la Corte. Las damas de la Corte de Honor de Zaragoza protagonizaron la lucha contra las escuelas laicas y el impulso de las católicas, y constituyeron el núcleo fundador de la Asociación de Damas de la Buena Prensa ${ }^{38}$. Pero su mayor éxito, a sus propios ojos, lo había constituido su participación en la protesta de 1906:

«De intento he dejado para lo último nuestro gran triunfo. Fue la Corte la primera colectividad de España que levantó la voz públicamente. Repartimos por toda la nación 20.000 hojas con valiente y enérgica protesta y más tarde preparamos una Comunión general de memoria imperecedera. No se recuerda otra más numerosa en el Pilar (...) La conducta de la Corte de Honor repercutió en toda España y en toda España se celebraron actos tan grandes de protesta que el proyecto de Ley no prosperó ${ }^{39}$.

De manera que, aunque la razón de ser inicial de la Corte de Honor se cifró en dar una respuesta a las agresiones anticlericales ocurridas en Zaragoza por medio del cultivo colectivo de la piedad, la oración y el culto, muy pronto diversificaron el repertorio de movilización, para incorporar actuaciones

37. El Pilar, $\mathrm{n}^{\circ}$ 1323, 21-XI-1908 (especial dedicado a la Corte de Honor en VI aniversario de su fundación). El Pilar, n 985, 5-VII-1902. Para los sucesos de 1901, véase El Pilar, $n^{\circ}$ 935, 20-VII-1901 y n ${ }^{\circ} 936,27-V I I-1901$.

38. Lo de la Buena Prensa, en El Pilar, no 1268, 14-XII-1907. Sobre su lucha contra las escuelas laicas, El Pilar, no 1230, 16-III-1907, p. 95.

39. El Pilar, $\mathrm{n}^{\circ} 1323$ ( $\mathrm{n}^{\circ}$ extraordinario dedicado a la Corte de Honor en su VI aniversario), 21-XI-1908, p. 402. 
abiertamente políticas. Tanto en una como en otra modalidad de acción se apeló, en tanto que recursos culturales de movilización, a las atribuciones de género en torno a la religión y a la piedad, es decir, a las concepciones sobre la mayor y más intensa religiosidad y piedad femeninas.

En cuanto a la Asociación Protección de Intereses Católicos, se estableció en Valencia en $1901^{40}$, cuando «espectáculos dolorosos (...) en la nación católica por excelencia, señaladamente en ciudad tan piadosa (...) lastimaron profundamente el corazón de las señoras valencianas». En este caso, lo que se buscaba era imprimir una dimensión más política al numeroso asociacionismo católico femenino piadoso y benéfico imperante en la ciudad para enfrentar la situación de amenaza a los «intereses católicos»:

«La experiencia advertía que faltaba un instrumento permanente para acudir con tiempo a la defensa de los intereses católicos, juntar en la acción a los buenos, allegar fondos, promover manifestaciones, difundir diarios católicos, promover instrucción popular, desengañar al vulgo, seducido por ruines políticastros, y, pues de señoras se trataba, para asistir a la obrera, librándola de las tres miserias que aquejan ordinariamente al pobre: la económica, la moral y la intelectual $\gg^{41}$.

En consecuencia, Intereses Católicos surgía, en comparación con la Corte de Honor, con un objetivo mucho más abiertamente político, de constituir una organización de acción católica que defendiera la religión y la Iglesia de los ataques anticlericales, y que promoviera, al mismo tiempo, la cultura e identidad católicas. Aunque sus fundamentos fueron las asociaciones piadosas y benéficas, el cultivo de la piedad, la extensión de cultos y devociones, o la celebración de desagravios por «agresiones cometidas contra la religión» parecían haber dejado de estar entre sus prioridades, desplazadas por una movilización eminentemente proselitista.

Una actividad nueva, que se apoyó también sobre la existencia de asociaciones previas, ejemplifica este paso del cultivo de la piedad al apostolado activo: la colaboración en la «buena prensa». Especialmente alentada por los publicistas católicos desde $1904^{42}$, se llamó directamente a las asociaciones

40. Para Ramiro Reig, las damas católicas valencianas constituyeron «una de las bases sociales más amplias y consistentes de la política católica». En REIG, Ramiro, Blasquistas y clericales. La lucha por la ciudad en la Valencia de 1900, Valencia, 1986; referencias a las damas católicas valencianas, en relación con la política republicana en esta ciudad, en SANFeliu, Luz, Republicanas: identidades de género en el blasquismo (1895-1910), Valencia, 2005, pp. 149-151 y 301-303.

41. NogueR, N., «Una gloria femenina de Valencia», Razón y Fe, mayo-junio, 1917, tomo 47, pp. 452-464 (aquí, pp. 452-453). La anterior cita, en p. 452.

42. Norberto Torcal, «La mujer católica no debe ser extraña a la obra de la Buena Prensa, la cual presta anchísimo campo a su piedad, a su caridad y a su celo» y «La Mujer y 
piadosas para que se implicasen en una actuación que desbordaba los límites de su habitual terreno de acción, en tanto en cuanto afectaba directamente a un ámbito público, como era la creación de opinión pública católica, y pretendía contribuir a minar el predicamento de la prensa liberal:

«Al menos, las asociaciones ya fundadas y que en todas partes existen haciendo tanto bien -las Conferencias de San Vicente de Paúl, las Hijas de María, el Carmen, el Rosario, las Madres Cristianas, tantas otras- debían abrir sus estatutos a esta necesidad imperiosa de las buenas lecturas y distribuirlas gratuitamente entre sus asociados y entre sus pobres y rogar por el triunfo de la buena prensa y reservar para ella algunas de sus limosnas» ${ }^{43}$.

Este tipo de actividad de nuevo cuño buscó desde su origen la permanencia y estabilidad a través de su institucionalización en asociaciones ${ }^{44}$. Inicialmente, se consideró idónea para aprovechar la influencia de esa figura de la madre moralizadora y catequizadora, puntal religioso y clerical dentro de la familia, que se enfrentaba no sólo a maridos propensos a recibir el «pernicioso» periódico liberal, sino a hijos cuya forma de razonamiento se mostraba indiferente ante la fe. En consecuencia, la implicación femenina en la Buena Prensa, tal y como se formuló inicialmente, se situaba a mitad de camino entre lo privado y lo público: se trataba de desplegar el rol materno dentro de la familia, pero al mismo tiempo, la dedicación a la buena prensa requería de una conciencia apostólica que se extendía más allá del hogar, preferentemente siempre dentro de los círculos de sus redes de relación social. Tampoco se descartaba una colaboración proselitista escribiendo en los periódicos:

la Prensa, por Dhammah», en Crónica de la Asamblea Nacional de la Buena Prensa, celebrada en Sevilla, en los días 15, 16, 17 y 18 de junio de 1904, pp. 249-270 y 404-409 respectivamente; LÓPEZ PELÁEZ, Antolín, «La mujer y la Prensa», Revista Católica de Cuestiones Sociales, $\mathrm{n}^{\circ} 157$, enero 1908, pp. 1-7 y n ${ }^{\circ} 158$, febrero 1908, pp. 65-72. Se trataba de una Conferencia del Obispo Jaca en el Centro Defensa Social Madrid impartida en noviembre 1907.

43. LE BRUn, J., La mujer y la prensa..., p. 24. «Hay en España muchos millares de hijas de María. Si sus directoras las instruyesen acerca de los medios de propagar la Prensa católica y del bien grandísimo que de ello resulta, ¿cómo dudar que cooperasen eficacísimamente en una empresa donde tan interesada se halla la gloria del Hijo benditísimo de la Virgen?», en «La mujer y la Prensa», Revista Católica de Cuestiones Sociales, $\mathrm{n}^{\circ}$ 158, febrero 1908, pp. 65-72 (aquí, p. 67).

44. Parece que surgieron primero en Zaragoza, Murcia, Valencia, Barcelona y Sevilla. En 1908, Echarri anunciaba que en «Madrid establece una que denomina Nacional y que desea se convierta en lazo común de todas ellas, ya que las aspiraciones son las mismas, el lema igual, e idénticos los fines que se persiguen, porque la unión entre todas nos llevará con mayor rapidez y más abundantes frutos a la victoria». Ilustración Católica, VIII, 10-IX-1908. 
«En este combate, toda mujer tiene un puesto. No hay rotativo anticlerical donde no colaboren mujeres; que hagan lo mismo en nuestros periódicos las señoras cristianas a quienes Dios haya distinguido con la preciosa dádiva del bien escribir. No es posible, no es posible diario de gran circulación sin una crónica o sección especial dedicada a asuntos femeninos y escrita por una mujer. Manda el Apóstol que las mujeres callen en la iglesia; pero obra de apóstoles pueden hacer hablando desde el periódico (...). No el escribir, sin embargo, sino el difundir los escritos es el principal papel que a las mujeres se reserva en esta campaña de salvación. En las visitas, en las tertulias, en todas sus relaciones sociales, deben hablar bien del buen periódico y recomendarlo a las personas sobre quienes ejercen influencia, y distribuirlo con la limosna que distribuyan a los pobres, y en su presupuesto de gastos consignar para el fomento de él la mayor partida posible» ${ }^{45}$.

Este tránsito de la dedicación piadosa a la implicación de rasgos más políticos no era tan natural y de fácil ejecución como pudiera parecer, pues las mujeres estaban excluidas de cualquier intervención política, y se las suponía reticentes a la misma. De ahí que se pusiera especial empeño en animar a las entidades piadosas a «ampliar su esfera de acción». Las contradicciones que podía suscitar dicho tránsito eran ilustradas (y resueltas) por el periodista católico zaragozano J. Le Brun como si de una «conversión personal» se tratara. En la introducción a un folleto en el que exhortaba a las mujeres a colaborar en la «buena prensa», y en un alarde literario, Le Brun abría su relato con la imagen romántica de una joven piadosa que había acudido al Pilar a hacer la vela a la Virgen, y «caía en el reclinatorio gozosa, transfigurada por la dicha de pasar aquella media hora junto a la Virgen». A pesar de proponerse concentrarse en la oración, el recuerdo de una noticia publicada recientemente en prensa la desvía de la misma, y la joven se ve envuelta en un diálogo interior entre una voz que le aconseja seguir rezando: «¿Qué te importa a ti de eso?...Tú reza», y la otra que insiste: «¿Que no le importa? ¿Que no le importa a ella? Pues si a ella, si a todas las cristianas como ella no les importa ¿a quién le importará?... ¿Es que será preciso callarse, aguantarse para siempre ante las desvergüenzas y los embustes de los malos periódicos?». La controversia interna continúa y acaban imponiéndose los argumentos de la segunda voz, la cual le lleva a adoptar el compromiso de «colaborar en la difusión de la buena prensa y a no comprar ni leer ningún diario o impreso que contenga escritos opuestos a mi fe y a la moral de mi madre la Iglesia católica» ${ }^{46}$. Lo interesante de este pequeño relato que precede al folleto exhortador a participar en la buena prensa es

45. LóPez Peláez, Antolín, «La mujer y la Prensa», Revista Católica de Cuestiones Sociales, 158, febrero 1908, pp. 65-72 (aquí, pp. 65 y 67).

46. LE BRUn, J., La mujer y la prensa..., p. VII. 
que plantea la cuestión del paso de la piedad a la política en términos de un conflicto entre la tradicional y aceptada dedicación exclusiva al cultivo de la piedad y la más novedosa y quizás menos apropiada implicación en una actividad de tintes proselitistas. Y que éste se resuelve curiosamente sin ningún tipo de mediación divina, a través del autoconvencimiento de la protagonista de que no sólo la situación exige su compromiso sino que también su posición y cualidades como sexo son las idóneas para desempeñar esta tarea.

\section{Conclusiones}

Si aspiramos a lograr un cuadro más completo y certero de la cultura política católica, resultaría imprescindible integrar un análisis atento a las atribuciones y percepciones de género existentes en el discurso y prácticas de los católicos. Dicho de otro modo, el movimiento católico que se reactivó en España a comienzos de siglo en respuesta ante la oleada anticlerical y la política laicizadora de los gobiernos liberales se articuló no sólo en torno a las amenazas anticlericales, o a determinados principios acerca de la relación entre política y religión, sino también alrededor de unas nociones de género precisas. Más aún, estas nociones de género estructuraron las visiones católicas sobre la familia, la religión, la piedad y la práctica política de las mujeres. Pero además, este tipo de análisis permitiría adentrarse en una comprensión mucho más polifacética del proceso de secularización, que tuviera más en cuenta las percepciones y temores de los contemporáneos acerca del impacto que dicho proceso estaba teniendo sobre el modelo católico de familia, los comportamientos considerados morales y las virtudes apropiadas exigidas a cada sexo.

En este artículo, tanto las novelas de María de Echarri como la abundante publicística católica que se elaboró en torno a las mujeres han revelado que, aunque el catolicismo se ocupó con particular obsesión de la definición de la feminidad ideal, ésta tuvo su complemento en un diagnóstico bastante apocalíptico sobre el estado de la masculinidad. Mientras que las mujeres parecían haber resistido, investidas de unas naturales virtudes que las predisponían a la fe, al embate de corrientes materialistas y revolucionarias, los hombres habrían sucumbido fácilmente ante las mismas. El diagnóstico de que la secularización había afectado casi en exclusiva a los hombres convirtió a las mujeres, en el discurso católico, en sujetos redentores de la deteriorada religiosidad masculina.

Y fue inicialmente en uno de los terrenos de expresión más acabada de religiosidad, el de la práctica piadosa, en el que las mujeres comenzaron a ejercer, cada vez con mayor combatividad y organización, ese rol de salvadoras. La persistencia de dicho discurso no sólo no impidió sino que favoreció 
tanto la ampliación de la esfera de acción de las entidades piadosas existentes como el surgimiento de nuevas organizaciones en defensa de los intereses católicos, es decir, con una finalidad abiertamente política. Las católicas fueron conscientes de que este tránsito del cultivo piadoso al proselitismo público y colectivo entraba en conflicto, aunque no fuera frontal, con las concepciones imperantes sobre las tareas y virtudes femeninas apropiadas. Un conflicto que la publicística católica se preocupó por resolver a través del convencimiento de que el móvil nunca había dejado de ser religioso, o de que la urgencia del momento exigía un esfuerzo de adaptación de la vieja feminidad ideal a las nuevas circunstancias. 